\title{
ROBUST CATALYTIC GAS SENSING USING A SILICON CARBIDE MICROHEATER
}

\author{
A. Harley-Trochimczyk*, A. Rao, H. Long, C. Carraro, and R. Maboudian \\ Berkeley Sensor \& Actuator Center and Department of Chemical \& Biomolecular Engineering \\ University of California, Berkeley, California 94720, USA
}

\begin{abstract}
This paper reports the first use of a silicon carbide ( $\mathrm{SiC}$ ) microheater for stable low-power catalytic gas sensing. Catalytic combustion of hydrocarbon gases often requires high operating temperatures, which leads to instability in a previously developed low-power polycrystalline silicon (polysilicon) microheater. A silicon carbide microheater has been developed with low power consumption $\left(20 \mathrm{~mW}\right.$ to reach $\left.500{ }^{\circ} \mathrm{C}\right)$ and improved stability, exhibiting an order of magnitude lower resistance drift than the polysilicon microheater after $100 \mathrm{hrs}$ of continuous heating at 500 ${ }^{\circ} \mathrm{C}$ and during temperature increases up to $650{ }^{\circ} \mathrm{C}$. When loaded with a high performance catalytic nanomaterial, the $\mathrm{SiC}$ microheater-based catalytic gas sensor exhibits fast response and recovery time $(<1 \mathrm{~s})$ and improved long-term stability for propane detection. The results show that a simple change of material from polysilicon to polySiC leads to a significant performance improvement of the microheater and the resulting sensor element.
\end{abstract}

\section{INTRODUCTION}

Catalytic gas sensing is important for personal safety and environmental monitoring in industrial and consumer settings. Current technology relies on a heated catalyst material, which promotes the catalytic combustion of the target gas. The resulting increase in temperature is detected by the sensing element, which in most cases is the same as the heater element. Due to the need for heating, commercially available catalytic gas sensors have a high power requirement $(>100 \mathrm{~mW})$, which prohibits this kind of sensor element from being battery-powered [1]. Miniaturization of the heater element can reduce the power consumption, but requires development of stable sensor elements and high performance catalytic materials to retain practical applicability.

Advancements in catalytic material design, including the recent development of an ultrahigh surface area, thermally stable boron nitride aerogel support for catalytic nanoparticles, has led to demonstration of fast and sensitive sensor response to combustible gases such as hydrogen and hydrocarbons [2,3]. However, at the temperatures required for effective activation of hydrocarbon combustion reactions $\left(500{ }^{\circ} \mathrm{C}\right)$, the previously developed polysilicon microheater suffers from poor reliability. The robust performance of $\mathrm{SiC}$ at high temperature combined with the tunable conductivity and temperature coefficient of resistivity (TCR) makes this material an attractive replacement for polysilicon [4]. Prior demonstration of $\mathrm{SiC}$ microheaters have confirmed their suitability for high temperature applications [5,6], including metal oxide-based gas sensing [7], but they have not been applied to catalytic gas sensing.

This paper details the fabrication of a low-power silicon carbide microheater, following nearly the same process flow as the polysilicon microheater. Comparison of the electrical behavior of the two microheaters shows significant improvements in performance when using $\mathrm{SiC}$, including lower resistance drift and full baseline recovery with changing temperatures. When an advanced catalytic material, platinum nanoparticle-loaded boron nitride aerogel, is integrated onto the $\mathrm{SiC}$ microheater platform, it can be used for propane detection with fast response and recovery $(<1 \mathrm{~s})$ and improved response stability.

\section{FABRICATION}

\section{Microheater Fabrication}

The microheater platform consists of four microheater elements per chip encapsulated in a low-stress silicon nitride membrane that is released through an anisotropic $\mathrm{KOH}$ back-etch (Figure 1a). The entire chip is $3.5 \times 3.5 \mathrm{~mm}^{2}$. The thin heater and membrane layers provide thermal isolation that keeps the power consumption low $\left(20 \mathrm{~mW}\right.$ to reach $\left.500{ }^{\circ} \mathrm{C}\right)$. An inset of one microheater in Figure $1 \mathrm{~b}$ shows the pink $\mathrm{SiC}$ trace. The heated area is found at the thinnest part of the trace to give an approximately $50 \times 50 \mu \mathrm{m}^{2}$ hot zone. The two white $\mathrm{Pt} / \mathrm{Ti}$ sensing electrodes are not used in this work and are masked with a thin layer of silicon dioxide before sensor testing to avoid interference from the platinum. Figure 1c shows a cross-sectional schematic of the microheater. The closed membrane facilitates deposition of sensing material on top of the microheater. The metal contacts to the heater are made off the membrane to keep them cool and stable.

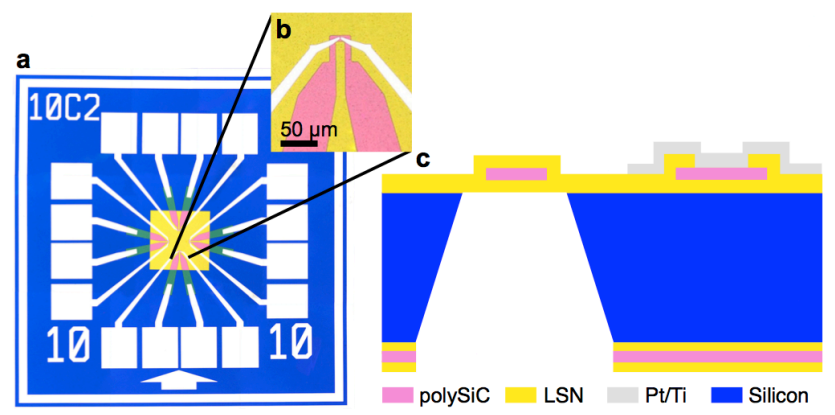

Figure 1. (a) Optical image of the chip $\left(3.5 \times 3.5 \mathrm{~mm}^{2}\right)$ consisting of four SiC microheaters. (b) Close-up of one microheater. (c) Schematic cross-section of microheater with polySiC encapsulated within back-etched low-stress silicon nitride (LSN) membrane with windows opened for Pt/Ti metal contacts (Pt/Ti).

Polysilicon microheater fabrication is described in detail elsewhere [2,3]. For the silicon carbide microheaters, the basic process flow is maintained and only the deposition and etch chemistries for the silicon carbide steps are changed. Briefly, lowstress silicon nitride (LSN) and silicon carbide films are deposited (Figure 2a), using methylsilane, hydrogen, and dichlorosilane as silicon carbide precursors in a low-pressure (170 mTorr) hot-wall reactor at $\mathrm{T}=835{ }^{\circ} \mathrm{C}$ with ammonia gas as the dopant source and the wafers in a closed-boat geometry with slots to limit the gas diffusion [8]. The deposited film is polycrystalline cubic 3C-SiC with a thickness of $130 \mathrm{~nm}$ and a sheet resistivity of 5,700 $\Omega /$ square. To define the microheaters (Figure $2 b$ ), the wafer is patterned with photolithography employing photoresist as the mask and reactive ion etching is done with $\mathrm{HBr}$ and $\mathrm{Cl}_{2}$ gases to selectively remove the $\mathrm{SiC}$ [9]. Using a transformer coupled plasma system, a high power of $300 \mathrm{~W}$ is needed to have an appreciable etch rate $(\sim 1.5 \mathrm{~nm} / \mathrm{s})$, so the etch is done in $10 \mathrm{~s}$ increments to prevent over-heating. A second silicon nitride layer is deposited (Figure 2c) and windows are etched to allow for metal contact to be made to the SiC (Figure 2d). The metal contacts are created through evaporation and lift-off (Figure 2e). Finally, a 
back-side window is etched to expose the silicon substrate (Figure $2 \mathrm{f}$ ), which is etched in a hot $\mathrm{KOH}$ bath to release the membrane (Figure 2g). The membrane ends up being approximately $200 \mathrm{~nm}$ thick through the LSN layers only.

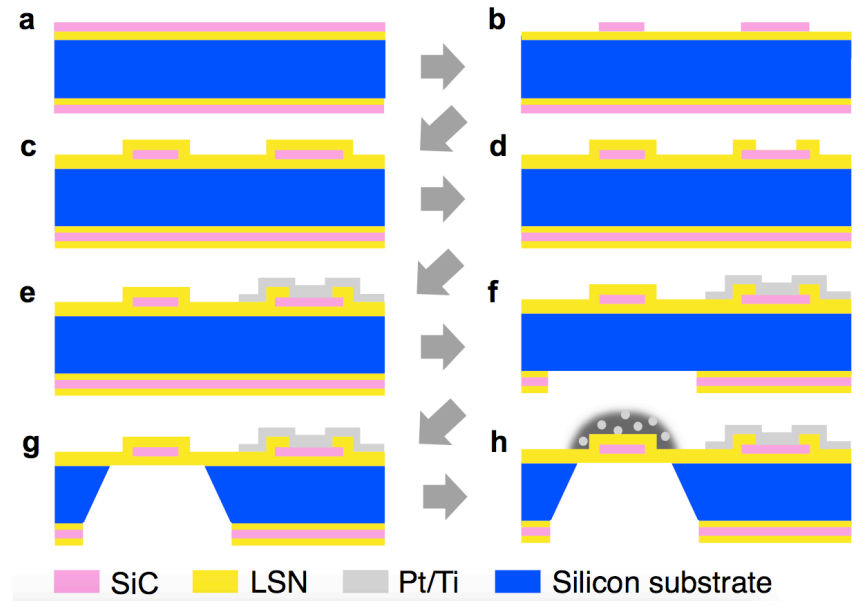

Figure 2. Silicon carbide microheater fabrication process. (a) Low pressure chemical vapor deposition of a low-stress silicon nitride (LSN) layer and doped SiC layer. (b) SiC is patterned and etched to form the microheaters. (c) A second LSN layer is deposited to encapsulate the microheaters. (d) A window is etched in the top LSN layer. (e) Metal contacts are created through photolithography, evaporation, and lift-off. (f) A window is etched in the back-side of the wafer. (g) The silicon substrate is etched with hot $\mathrm{KOH}$ to release the membrane. (h) Catalytic material is deposited on the microheater for catalytic gas sensing.

\section{Microheater Testing}

The microheater testing is done with a Keithley 2602A source-meter. LabTracer 2.9 software is used to run the currentvoltage traces. An open-source Java-based program called Zephyr is used for the continuous power and variable temperature tests. The microheater temperature is linearly proportional to applied power in the operating range. Measuring the heater resistance during external heating does not provide an accurate temperature calibration because the colder parts of the heater contribute a nonnegligible portion of the total resistance. Therefore, external heating where the entire chip is at a given temperature does not provide the same resistance as when only the hot zone of the microheater is at that temperature. Instead, temperature calibration of the microheaters is done by powering the heater to glowing and then fitting the emission spectrum with a Planck distribution [10]. The onset of visible glow is found to be $\sim 700{ }^{\circ} \mathrm{C}$ which is $21 \mathrm{~mW}$ for the polysilicon microheaters and $28 \mathrm{~mW}$ for the $\mathrm{SiC}$ heaters.

\section{Nanoparticle-decorated Aerogel Synthesis}

The platinum nanoparticle-loaded boron nitride aerogel (Pt$\mathrm{BN})$ synthesis can be found in full detail in Ref. 3. Briefly, graphene oxide sheets are cross-linked into a gel, dried with supercritical $\mathrm{CO}_{2}$ to retain the high surface area, and pyrolyzed at high temperature for graphitization. The resulting high surface area graphene aerogel undergoes carbothermic reduction in the presence of $\mathrm{B}_{2} \mathrm{O}_{3}$ vapor and $\mathrm{N}_{2}$ gas at high temperature (1600-1800 ${ }^{\circ} \mathrm{C}$ ) to form the boron nitride aerogel with a specific surface area of $450 \mathrm{~m}^{2} / \mathrm{g}$. The platinum nanoparticle loading is done by infiltrating the aerogel with a $0.5 \mathrm{M}$ solution of chloroplatinic acid $\left(\mathrm{H}_{2} \mathrm{PtCl}_{6}\right)$ in ethanol and annealing under Ar at $600{ }^{\circ} \mathrm{C}$ for $2 \mathrm{hr}$ to thermally reduce the $\mathrm{Pt}$ complex to pure $\mathrm{Pt}$ metal nanoparticles.

\section{Sensor Fabrication and Testing}

For sensor testing, an individual chip is wire-bonded into a ceramic dual in-line package. The Pt-BN is sonicated into suspension in isopropyl alcohol and a few microliters are dropped onto the chip while the microheater is heated to $80{ }^{\circ} \mathrm{C}$ to facilitate local deposition at the heated spot. The packaged sensor is exposed to gas in a $1 \mathrm{~cm}^{3}$ chamber. Propane ( $5 \%$ in $\mathrm{N}_{2}$, Praxair), oxygen, and nitrogen gas flow rates are controlled with Bronkhurst mass flow controllers and Labview. The oxygen content is controlled at $20 \%$ and the total gas flow rate is held to $300 \mathrm{sccm}$. A Keithley 2602A source-meter and Zephyr software are used to control the sensor and record the sensor response. Sensing response is reported as $\left(\mathrm{R}-\mathrm{R}_{0}\right) / \mathrm{R}_{0} \times 100 \%$ where $\mathrm{R}$ is the sensor resistance during exposure to a given concentration of propane and $\mathrm{R}_{0}$ is the sensor resistance in dry air only.

\section{RESULTS AND DISCUSSION \\ Microheater Characterization}

The current-voltage sweeps of the $\mathrm{SiC}$ and polysilicon microheaters are shown in Figure 3. The $\mathrm{SiC}$ microheaters have a higher resistance, about $35 \mathrm{k} \Omega$ compared to $2 \mathrm{k} \Omega$ for the polysilicon microheaters. To reach the same applied power, the $\mathrm{SiC}$ microheaters require higher applied voltages, which is why the potential sweep goes to $30 \mathrm{~V}$ compared to $5 \mathrm{~V}$ for polysilicon. The microheaters also have different power requirements to reach 500 ${ }^{\circ} \mathrm{C}(15 \mathrm{~mW}$ for polysilicon versus $20 \mathrm{~mW}$ for $\mathrm{SiC})$, which is attributable to the higher thermal conductivity of $\mathrm{SiC}$ compared to polysilicon [4]. The slight increase in power consumption can be offset through heater duty cycling, where the heater is turned on for only short time periods. The two microheaters have temperature coefficients of resistance that are opposite in sign, with the polysilicon resistance increasing with temperature $(+350$ $\mathrm{ppm} / \mathrm{K})$ and the $\mathrm{SiC}$ resistance decreasing with temperature $(-700$ $\mathrm{ppm} / \mathrm{K})$, which is comparable to previous work [11]. The sign of the microheater TCR is controlled by the competing effects of increased phonon scattering in the crystal grain (increasing resistance with temperature) and thermal activation of carriers through the grain interfaces (decreasing resistance with temperature). The magnitude of the $\mathrm{SiC} \mathrm{TCR}$ is twice as high as the polysilicon, which becomes important for sensitivity during combustible gas sensing because the same change in temperature due to gas combustion results in a larger resistance change from $\mathrm{SiC}$ than from polysilicon.
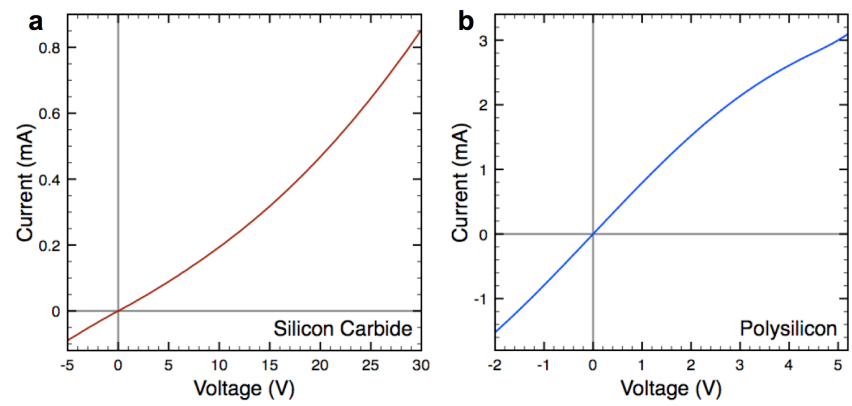

Figure 3. Current-voltage sweeps for (a) SiC and (b) polysilicon microheaters.

When both microheaters are powered to $500{ }^{\circ} \mathrm{C}$ for 100 hours (Figure 4), the $\mathrm{SiC}$ microheater has an order of magnitude lower drift $(-0.6 \%)$ than the polysilicon (7\%). The higher noise in the $\mathrm{SiC}$ microheater may be due to the lower current level used due to the higher resistance. Previous reports have shown a similar long-term positive resistance drift of polysilicon at temperatures around 500 ${ }^{\circ} \mathrm{C}[12,13]$. The cause may be dopant diffusion along the 
temperature gradient in the polysilicon layer or dopant segregation at grain boundaries. Over the first 100 hours, there is some decrease in the rate of drift and it is possible that with a long "burn-in" or conditioning time, the drift can be mitigated. However, during catalytic gas sensing, the heat of combustion leads to an increase in the heater temperature above the $500{ }^{\circ} \mathrm{C}$ baseline, so even with stability in the baseline, the microheater behavior with changing high temperature is the most critical to practical use.

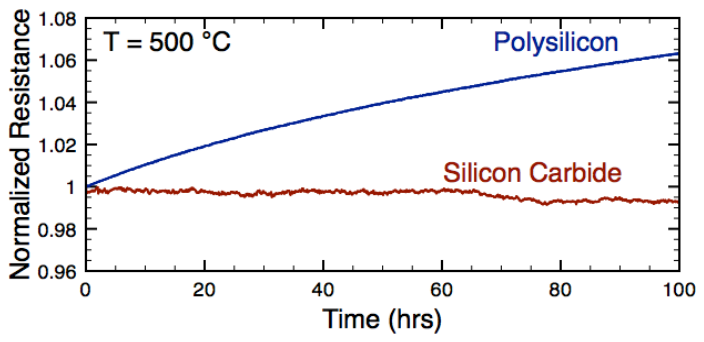

Figure 4. Normalized resistance of $\mathrm{SiC}$ and polysilicon microheaters continuously powered to $500^{\circ} \mathrm{C}$ for 100 hours.

To demonstrate this issue, applying a set of temperature changes between 10 to $150{ }^{\circ} \mathrm{C}$ above the $500{ }^{\circ} \mathrm{C}$ baseline (Figure $5 a)$ results in major instability in the polysilicon microheater, including history dependence (Figure 5b). The same type of drift behavior is reported previously from a polysilicon heater element when the heater temperature is increased and decreased in a stepwise manner [12]. The authors also found that the resistance at low temperature depends on the high temperature previously reached by the polysilicon heater and the cooling rate back to low temperature [12]. Given how the resistance of the polysilicon microheater changes when it is returned to the $500{ }^{\circ} \mathrm{C}$ baseline from various high temperatures, this pattern appears to hold.

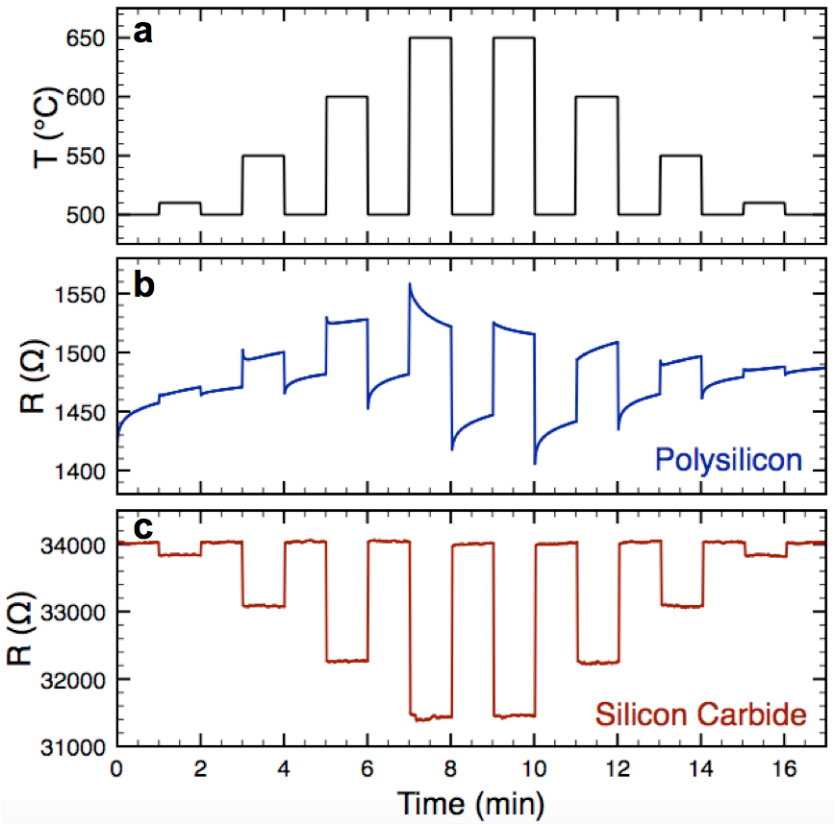

Figure 5. (a) Temperature profile applied to the microheaters and resulting (b) polysilicon and (c) SiC microheater resistance.

In contrast to this unpredictable behavior, the $\mathrm{SiC}$ microheater displays no such instabilities, showing stable baseline recovery even after being heated to $650^{\circ} \mathrm{C}$ (Figure $5 \mathrm{c}$ ). The wide bandgap and high chemical stability of silicon carbide make it highly resistant to thermally induced resistance drift and the superior choice for a sensing platform to be operated at high temperature.

\section{Sensing Response}

With the addition of Pt-BN (Figure 6a), the SiC platform can be used for catalytic gas sensing. Propane, a commonly used fuel, refrigerant, and process chemical, is used to demonstrate the sensor performance. Although the auto-ignition temperature for propane is $450{ }^{\circ} \mathrm{C}$, there is no response without adding a catalytic material like Pt-BN to the microheater. Other researchers have shown that small microheater-based sensors are explosion-proof without the need for expensive packaging [14]. Propane has a lower explosive limit (defined as the lowest concentration capable of producing an explosion) of $2.1 \%$ or $21,000 \mathrm{ppm}$; thus, the sensor is exposed to concentrations below that value.

Figure 6a shows the Pt-BN drop-casted on top of the silicon carbide microheater. TEM images of the Pt-BN show that the average Pt nanoparticle size is $17 \pm 6 \mathrm{~nm}$ and the lattice spacing is consistent with pure Pt metal [3]. High resolution TEM images also show that the boron nitride aerogel scaffold is 7-10 layers thick [3]. The high specific surface area allows for high nanoparticle loading with minimal support mass, improving the transfer efficiency of the heat generated during hydrocarbon combustion.
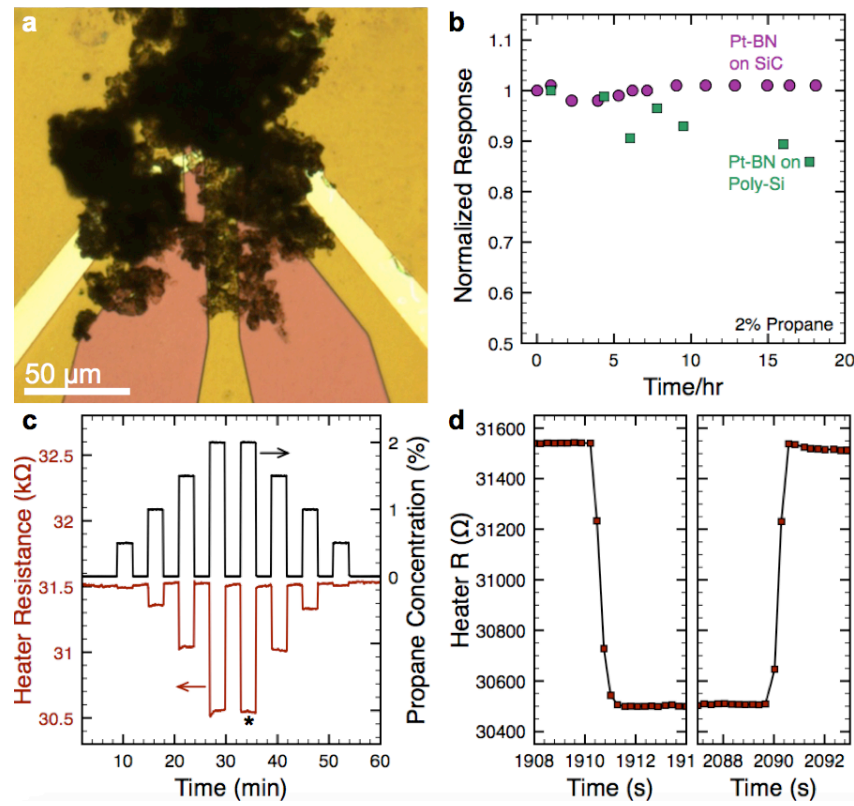

Figure 6. (a) Optical image of the Pt-BN catalyst drop-casted on top of the microheater. (b) Pt-BN SiC sensor response to 2\% propane over 18 hours of operation compared to Pt-BN on the polysilicon microheater. (c) Response to varied propane concentrations for Pt-BN SiC sensor versus time showing good baseline stability and response reproducibility. (d) Pt-BN SiC sensor response and recovery time for $2 \%$ propane $\left(t_{90}<1 \mathrm{~s}\right)$.

The Pt-BN SiC sensor shows good response to propane with a heater temperature of $500{ }^{\circ} \mathrm{C}$ (Figure 6c) with a larger sensitivity than Pt-BN on polysilicon [3], thanks to the larger TCR of SiC. The baseline resistance of the Pt-BN $\mathrm{SiC}$ sensor shows good stability and the sensor recovers well to the baseline after gas exposure. The gas exposures also show good reproducibility. The sensor detection limit is just below 5,000 ppm propane at this operating temperature. The $\mathrm{SiC}$ platform can be used at higher 
temperatures, which may allow for an improved limit of detection. Figure 6d shows a close up view of the starred response in Figure $6 \mathrm{c}$ when exposed to $2 \%$ propane and the subsequent recovery when the gas is switched back to clean air. The times to reach $90 \%$ of the full signal levels $\left(\mathrm{t}_{90}\right)$ for response and recovery of the Pt-BN SiC sensor are very fast $(<1 \mathrm{~s})$, comparable to prior reports [2, 3].

The response is highly stable over an 18-hour period of extended continuous operation where the sensor is exposed to clean air and various concentrations of propane (Figure 6b). The response to $2 \%$ propane is shown in Figure $6 \mathrm{~b}$ for clarity, even though the sensor is exposed to varied concentrations during this test. Figure $6 \mathrm{~b}$ shows a drop-off in response of about $15 \%$ in the first 18 hours for Pt-BN on a polysilicon microheater. With the SiC microheater platform, there is no drop in response over the same period of time. Just as prior work demonstrates an improvement in response stability through selection of a more thermally stable aerogel material (boron nitride instead of graphene), this work demonstrates the significant benefit of a thermally stable material in the microheater platform (silicon carbide instead of polysilicon).

\section{CONCLUSIONS}

Miniaturized microheater-based catalytic gas sensors can provide low-power consumption, but stable and reliable performance is critical for practical use. Switching from a polysilicon microheater element to one fabricated with polycrystalline silicon carbide allows for much improved performance during high temperature operation. The $\mathrm{SiC}$ microheater shows much more stable resistance during continuous heating at $500{ }^{\circ} \mathrm{C}$ and during temperature changes from $500{ }^{\circ} \mathrm{C}$ up to $650{ }^{\circ} \mathrm{C}$. When a thermally stable catalytic material (platinum nanoparticle-loaded boron nitride aerogel) is added, propane detection with good reproducibility and response stability over 18 hours and fast response and recovery time $(<1 \mathrm{~s})$ is demonstrated.

\section{ACKNOWLEDGEMENT}

The authors acknowledge Thang Pham and Prof. Alex Zettl for the synthesis of the platinum nanoparticle-loaded boron nitride aerogel. The authors would additionally like to thank Dr. Qin Zhou and Dr. Jiyoung Chang for assistance with the design and fabrication process development for the polysilicon microheaters. This work is supported by the Berkeley Sensor \& Actuator Center and the National Science Foundation Accelerating Innovation Research-Technology Transfer program (IIP 1444950). A. H.-T. and H. L. acknowledge further support from the NSF Graduate Research Fellowship (DGE 1106400) and the China Scholarship Council, respectively.

\section{REFERENCES}

[1] SGX Sensortech, "VQ548MP Datasheet, DS-0140 Issue 2", (2014).

[2] A. Harley-Trochimczyk, et al., "Low Power MicroheaterBased Combustible Gas Sensor with Graphene Aerogel Catalyst Support", Technical Digest of the $18^{\text {th }}$ International Conference on Solid-State Sensors, Actuators, and Microsystems, Anchorage, AL, 6/21-25/15, Transducer Research Foundation, Cleveland (2015), pp. 1483 - 1486.
[3] A. Harley-Trochimczyk, et al., "Platinum Nanoparticle Loading of Boron Nitride Aerogel and Its Use as a Novel Material for Low-Power Catalytic Gas Sensing", Advanced Functional Materials, 26, 433 (2016).

[4] R. Maboudian, C. Carraro, D. G. Senesky, and C. S. Roper, "Advances in silicon carbide science and technology at the micro- and nanoscales", J. Vac. Sci. Technol. A. 31, 050805$1,(2013)$.

[5] L. Chen and M. Mehregany, "An Examination of MaterialRelated Performance in SiC Heated Elements for IR Emitter and Sensor Applications", Materials Science Forum, 600, 863 (2009).

[6] S. Noh, J. Seo, and E. Lee, "The Fabrication by Using Surface MEMS of 3C-SiC Micro-heaters and RTD Sensors and their Resultant Properties", Trans. Electr. Electron. Mater. 10, 131 (2009).

[7] F. Solzabacher, C. Imawan, H. Steffes, E. Obermeier, and M. Eickhoff, "A Highly Stable $\mathrm{SiC}$ Based Microhotplate $\mathrm{NO}_{2}$ Gas Sensor", Sens. and Actuators B, 78, 216 (2001).

[8] F. Liu, C. Carraro, A. P. Pisano, and R. Maboudian, "Growth and characterization of nitrogen-doped polycrystalline $3 \mathrm{C}-\mathrm{SiC}$ thin films for harsh environment MEMS applications", J. Micromech. Microeng., 20, 035011 (2010).

[9] D. Gao, R. T. Howe, and R. Maboudian, "High-selectivity etching of polycrystalline 3C-SiC films using $\mathrm{HBr}$-based transformer coupled plasma", Appl. Phys. Lett., 82, 1742 (2003).

[10] Q. Zhou, A. Sussman, J. Chang, J. Dong, A. Zettl, and W. Mickelson, "Fast response integrated MEMS microheaters for ultra low power gas detection", Sens. and Actuators A, 223, 67 (2015).

[11] J. Zhang, R. T. Howe, R. Maboudian, "Electrical Characterization of n-Type Polycrystalline 3C-Silicon Carbide Thin Films Deposited by 1,3-Disilabutane", J. Electrochem. Soc., 153, G548 (2006).

[12] M. Ehmann, F. Schubert, P. Ruther, and O. Paul, "Thermally Activated Ageing of Polysilicon", IEEE Sensors, 1, 601 (2002).

[13] O. Grudin, R. Marinescu, L. Landsberger, D. Cheeke, and M. Kahrizi, "Microstructure Release and Test Techniques for High-Temperature Micro Hotplate", Proceedings of the 1999 IEEE Canadian Conference on Electrical and Computer Engineering, Edmonton, Canada, 5/9-12/99, pp. 1610-1615.

[14] C. Ducso, M. Adam, P. Furjes, M. Hirschfelder, S. Kulinyi, I. Barsony, "Explosion-proof monitoring of hydrocarbons by mechanically stabilized, integrable calorimetric microsensors", Sens. and Actuators B, 95, 189 (2003).

\section{CONTACT}

*A. Harley-Trochimczyk, tel: +1-510-643-3489; anna.harleytr@berkeley.edu 